\title{
CHLORDECONE ADSORPTION ON FUNCTIONALIZED ACTIVATED CARBONS: COMPUTATIONAL CHEMISTRY AS A TOOL FOR UNDERSTANDING THE ADSORPTION PROCESS
}

\author{
Kenia Melchor-Rodríguez ${ }^{\mathrm{a}}$, Sarra Gaspard ${ }^{\mathrm{b}}$ and Ulises Javier Jáuregui-Haza ${ }^{\mathrm{a}, \mathrm{c}, *, \text {,(1) }}$ \\ anstituto Superior de Tecnologías y Ciencias Aplicadas, Universidad de La Habana, Avenida Salvador Allende, 1110, Quinta de \\ los Molinos, Plaza de la Revolución, A.P. 6163, La Habana, Cuba \\ 'Département de Chimie, Université des Antilles, BP 250, 97159 Pointe à Pitre Cedex, Guadeloupe \\ 'Instituto Tecnológico de Santo Domingo, Avenida de los Próceres. Santo Domingo, República Dominicana
}

Recebido em 30/04/2020; aceito em 21/09/2020; publicado na web em 06/11/2020

\begin{abstract}
Chlordecone (CLD) has been used as a pesticide for a long time to control the proliferation of various insects in tropical countries like the French West Indies. CLD was included in 2009 in the list of persistent organic pollutants (POPs) by the Stockholm Convention, prohibiting its production and use worldwide. Thus, its removal from water and soils is a sanitary emergency. With the purpose of limiting impregnation of the population by chlordecone in Martinique and Guadeloupe, since 1999 production and drinking water purification installations have been equipped with activated carbon filters without much knowledge on the adsorption mechanism of these pollutants on activated carbons (AC) surface. This article reviews the available information about how functionalized activated carbons can be used for improving the decontamination of polluted with CLD waters. The recent computational investigations about the CLD interactions with functionalized AC by molecular modeling are well-reviewed, considering geometrical and energetic features with the purpose of better understand the adsorption process. Finally, some aspects, trends, and perspectives on using computational tools for understanding the adsorption of CLD on AC and designing more efficient AC are also discussed.
\end{abstract}

Keywords: adsorption; activated carbons; pesticides; chlordecone; computational chemistry.

\section{INTRODUCTION}

The development of agriculture has led to the parallel rise worldwide of the use of pesticides, causing harmful effects on the health of living organisms. These compounds are released into the environment and can be dispersed between organic matter (in soil or sediments) and water. ${ }^{1-4}$ Pesticides are used to control the proliferation of pests in agricultural crops and products, to protect not only the plants, also the animals and the humans.

Chlordecone (CLD, global formula $\mathrm{C}_{10} \mathrm{Cl}_{10} \mathrm{O}$ ), an organochlorinated synthetic compound, was extensively used around the world as a pesticide between 1951 and $1975 .{ }^{5}$ But, due to the persistence of CLD in natural environmental the presence and distribution of CLD in waters, soils, sediments, the food chain, as well as its risky consequences for the environment and human health, have been studied by several authors in recent years. ${ }^{6-17}$

Between the 1960s and the 1990s, there was a large-scale increase in the production of bananas in Guadeloupe and Martinique which required the in-depth use of chlordecone, causing a diffusion of the contamination by this pesticide in soils and surface waters in agriculture zones. ${ }^{18}$ For that reason, the greatest ecological urgency regarding this pesticide has been widely reported until nowadays. ${ }^{6,18-26}$ Therefore, there is currently an increasing social and political pressure to encounter alternative sustainable processes that preferentially adsorb and decompose chlordecone into non-polluting compounds. In this sense, the drinking water plants production use activated carbon filters with the objective of limiting the exposure by CLD to the population of the French West Indies. ${ }^{27}$

Regarding the adsorption of CLD in AC for the treatment of contaminated water with this pesticide in Guadeloupe and Martinique, there are two main reports to date. First, Durimel et al. ${ }^{18}$ studied the use of activated carbons obtained from sugarcane bagasse, with

*e-mail: ulises.jauregui@intec.edu.do different physicochemical properties, for the treatment of water contaminated with CLD. As results, it was demonstrated that the highest amounts of chlordecone can be adsorbed in acid AC, which indicated a higher affinity of this pesticide for acid surface functional groups of the studied activated carbons. While Rana et al.,${ }^{28}$ modified the surface of $\mathrm{AC}$ with nanoparticles of $\mathrm{FeO}$ to increase the adsorption of CLD. However, the experimental procedures to evaluate the most suitable adsorbent consume a lot of material resources and time due to the high amount of different AC that to be tested..$^{18,29,30} \mathrm{On}$ the other hand, "the adsorption process onto activated carbon is a very complex phenomenon driven by multiple factors ranging from the chemical composition to the texture properties of the AC. The influence of the surface group content on the adsorption properties has been reported and studied to a certain extent both theoretically and experimentally for the porous carbons, mainly AC'. ${ }^{27}$ For this reason, and with the aim of obtaining more efficient and specific adsorbents, computational and theoretical chemistry play a crucial role in the design of more specific and efficient adsorbents with modified surface groups. However, it should be noted that, until nowadays, no work has been published in the literature that summarizes the most significant advances in the application of computational and theoretical methods with the objective to better understanding the adsorption mechanism of CLD onto functionalized AC.

This review aims to demonstrate how computational chemistry has been used to characterize the interactions of CLD molecule and acidic surface groups onto AC taking into consideration the $\mathrm{pH}$ and hydration effect, with the intention of understand the adsorption mechanics and to corroborate experimental results. On the other hand, a computational methodology for evaluating AC surface groups influence over the adsorption process of CLD on AC is presented. It has been positively applied in the characterization of the main interaction types for $\gamma$ and $\beta$ isomers of hexachlorocyclohexane, paracetamol and ${ }^{125}$ I-paracetamol adsorption in analogous systems. ${ }^{27,31}$ 


\section{COMPUTATIONAL METHODS}

\section{Computational chemistry as a tool for understanding the adsorption process of CLD onto AC}

Some years ago, the techniques of computational and theoretical chemistry were used only by experts extremely experienced in the use of the tools they offer, which in most cases were difficult to understand and apply. However, at present, advances in software have produced programs that are more easily used by any chemist.

The use of computational chemistry allows reducing the delays for developing and obtaining new products; optimizing existing processes to improve energy efficiency and minimizing wastes. It also allows the efficient design of new processes and products; improving health, social welfare and environmental conditions; understanding what is happening and predicting phenomena at nano and picoscales. In this sense, computational chemistry plays an important role in understanding the adsorption process of CLD onto functionalized $\mathrm{AC}$ under different $\mathrm{pH}$ and hydrated conditions and for the design of specific modifications that guarantee the production of more efficient and specific adsorbents for removing chlordecone from water, improving the $\mathrm{AC}$ selection process.

\section{A computational approach for studying interactions of pollutants with surface groups of $\mathrm{AC}$}

For the evaluation of the adsorption energies of the guest molecules in carbon-based material models, computational methods have been widely used. However, the description of interactions between adsorbant and AC surfaces still represents a challenge for the scientific community using current theoretical techniques. ${ }^{27}$

Concerning that, a general computational methodology has been proposed by the authors that consist in two main steps. ${ }^{27,31,32}$ First, the Multiple Minima Hypersurface methodology (MMH) is used to explore the configurational space of the CLD interactions with the selected acid surface groups onto activated carbon. Afterwards, distinctive minima structures are selected that represent the possible types of interaction in the systems under study. The condition, for the geometrically representative structures selection is based on general chemical knowledge, in view of the structures of global minimums and local minimums, close to latter. Second, the selected distinctive minima structures obtained from $\mathrm{MMH}$ are re-calculated using the Density Functional Theory (DFT), for obtaining an optimal quality electronic geometry and structure that permit characterize the nature of present interactions in the systems under study: SG/CLD (surface groups of AC interacting with CLD) and $\mathrm{SG} / \mathrm{CLD} /\left(\mathrm{H}_{2} \mathrm{O}\right)_{\mathrm{n}=1-3}$ (surface groups of $\mathrm{AC}$ interacting with CLD and one or more water molecules). Finally, the Quantum Theory of Atoms in Molecules (QTAIM), is used in order to more accurately describe the nature of the interactions present in the systems under study. Recently, molecular modeling studies of chlordecone interactions with activated carbons surface functional groups have been published using this methodology. ${ }^{32,33}$

$\mathrm{MMH}$ procedure "combines quantum mechanical methods for the calculations of energy with statistical mechanics to obtain thermodynamic parameters related to the molecular association process. This methodology is a very helpful and reliable approach for localizing the minima of weakly interacting systems and, for that reason, it has been successfully employed in several studies". ${ }^{34}$ In fact, Durimel et al. ${ }^{18,19}$ and Enriquez-Victorero et al. ${ }^{27}$ have published theoretical results of chlordecone and $\beta$-hexachlorocyclohexane interactions with activated carbons surface functional groups using $\mathrm{MMH}$ methodology. The specific modifications and the main procedure of this approach has been described in details in previous works. ${ }^{27,31,32,33}$
In standard $\mathrm{MMH}$ procedure, the solute is situated in the center of a cubic box with a specific dimension (depending on system under study). Then, the system generates solvent molecules in several random configurations. Through this procedure, the space region for generated solvent molecules cannot be restricted. For that reason, the standard MMH methodology was modified that one may implement a geometric restriction in cells generation. This geometric restriction is a useful tool to avoid wasting computational resources exploring space zones with no particular interest or those corresponding with physically unrealistic representations of the systems. ${ }^{35}$

On the other hand, three thermodynamic properties, association energy $\left(\Delta \mathrm{E}_{\mathrm{ASSOC}}\right)$, association entropy $\left(\Delta \mathrm{S}_{\mathrm{ASSOC}}\right)$, and Helmholtz free energy $\left(\Delta \mathrm{A}_{\mathrm{ASSOC}}\right)$ can be calculated by $\mathrm{MMH}$ procedure. However, the association energy was used for evaluating the stability of the systems under study. It is defined as $\Delta E_{A S S O C}=E_{\text {supermolecule }}-E_{\text {ref }}$, where $E_{\text {supermolecule }}$ is the energy of formed molecular complex by the activated carbon model (with and without SGs) and the interacting in the studied system molecules (in this case: CLD and water) and $E_{\text {ref }}$ is the energy of the isolate molecules. When the stability of the supermolecules are greater than the isolated molecules it implies an agreeable thermodynamic association. In view of that, the molecular energy is negative, then $\Delta E_{A S S O C}$ will be negative, thus, a major absolute value of $\Delta E_{A S S O C}$ is in correspondence to more energetically favorable association.

Generally, MMH methodology is based on semiempirical methods. Taking into account that, the semiempirical Hamiltonian $\mathrm{PM} 7^{36}$ enhances the description of dispersive interactions and hydrogen bonds, compared to preceding semiempirical procedures, ${ }^{37}$ it was selected for the optimization of the geometries under study, as implemented in MOPAC2012 (used by Gamboa-Carballo et al.) ) $^{32,38}$ and MOPAC2016 (used by Melchor-Rodríguez et al.) ${ }^{33,39}$ programs. In all calculations the eigenvector-following routine " $\mathrm{EF}$ " for searching minima was used.

Since, DFT has posed itself as one of the most popular and versatile methods available for the study of electronic structure of innumerable systems, it was used for the re-optimization of the geometries of the systems under study obtained by $\mathrm{MMH}$ procedure. This is the second step of the computational methodology. The basic idea of DFT is that "the energy of an electronic system can be written in terms of the electron probability density, $\rho$. For a system of $\mathrm{N}$ electrons, $\rho(r)$ denotes the total electron density at a particular point in space. The electronic energy $E$ is treated as a functional of the electron density, in the sense that for a given function $\rho(r)$, there is a single corresponding energy". ${ }^{40}$

DFT has become the dominant procedure with several advantages and it presents an encouraging option to high-level correlated $a b$ initio theories. However, the selection of the functional that can properly describe your system is essential, in order to obtain good results. Therefore, it is recommended as a good practice to do a previous search using the scientific literature for calculation on similar systems and properties and to select the best functional that has been previously well tested. Taking into account that, two DFT functionals have been used for study CLD interaction with AC surface groups. Gamboa-Carballo et al., ${ }^{32}$ used Becke's three parameter hybrid method using the correlation functional of Lee, Yang and Parr with the Coulomb-attenuating long-range correction CAM-B3LYP, ${ }^{41,42}$ and the Pople's basis set 6-31+G(d,p). They used this functional for evaluating the interactions of CLD and acidic AC surface groups at acidic and neutral $\mathrm{pH}$. However, seeing the accuracy of Minnesota functionals, Melchor-Rodríguez et al., ${ }^{33}$ employed the M06-2X functional ${ }^{43}$ for the optimization of specific geometries and for evaluating the interactions of chlordecone hydrate (CLDh) with AC acidic surface groups at basic $\mathrm{pH}$. The basis set for M06-2X functional was the 
same as that used for CAM-B3LYP. M06-2X has been reported as the best functional for a combination of main-group thermochemistry, kinetics, and noncovalent interactions. ${ }^{44,45} \mathrm{M} 06-2 \mathrm{X}$ is "parametrized only for nonmetals, for calculating the relative conformer energies and geometric structures of anionic systems that potentially contain important contributions from dispersion interactions", that is the case of CLD-AC systems. Also, it had been demonstrating that "M06-2X gives a best performance in charge transfer complexes that have long been recognized as a difficulty for density functionals". ${ }^{46}$

In a view that, there is not an objective of the present review to more accurately explain the theoretical description, advantages and disadvantages of both functionals described here, more information can be found in specialized literature. ${ }^{41-48}$ However, the selected keywords of DFT input files are presented: 1) EmpiricalDispersion =GD3: a method correction to better describe non-covalent interactions; 2) $\mathrm{Opt}=($ CalcAll, Cartesian $)$ : optimize the structures minimizing them with a quadratic convergence (Newton specification) and using Cartesian coordinates (Cartesian specification), both specifications make the calculations safer; 3 ) Int=UltraFine: utilized to increase the numerical accuracy, even though it is more expensive; 4) NoSym: this indicates that the symmetry of the geometry will not be used, nor that the electrons, in order to accelerate the calculations and make it more reliable and, 5) $S C F=Q C$ : to close the Self-Consistent Field (SCF) when the structures do not converge. Computational calculations have been performed using Wahoo, the cluster of the Centre Commun de Calcul Intensif of the Université des Antilles, Guadeloupe, France.

Finally, the electronic density is re-optimized using the Pople basic set $6-311++\mathrm{G}(2 \mathrm{df}, 2 \mathrm{pd})$, as implemented in Gaussian $09,{ }^{49}$ in order to achieve a better description of studied interactions. After that, the distinctive minima structures and their electronic configurations were analyzed by QTAIM ${ }^{50}$ for characterizing the nature of chemical bonds and interactions that take place during the adsorption process. QTAIM permits to characterize electron density topology and its Laplacian at bond critical points (BCPs). It also helps to describe and classify intermolecular interactions from weak to strong, using different accepted criteria. In this case, the Nakanishi's criteria were used. ${ }^{51,52}$ These calculations were made using the Multiwfn 3.6 program.

Summarizing, the first and the most important step to qualitatively describe the association of the pollutant with activated carbon surface groups is the use of MMH methodology. This methodology was used to explore the energy hypersurface using a semiempirical Hamiltonian (PM7) and subsequently find stationary points of minimum energy which significantly contribute to the thermodynamic properties of the system. From the full set of minima structures obtained by MMH methodology, it was selected a set of structures that represent distinctive interactions. Then, a DFT re-optimization was performed (b)

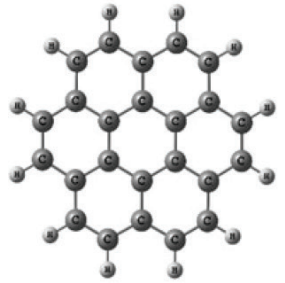

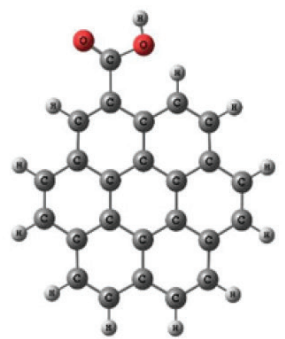

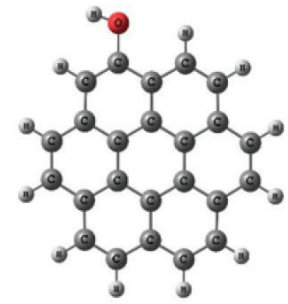

in order to obtain a better representation of the electron density to characterize the nature of the molecular interactions using QTAIM.

\section{RESULTS AND DISCUSSION}

\section{Recent computational results of chlordecone interactions with activated carbons acidic surface functional groups}

Theoretical models that can properly describe the AC constitution, morphology and topology generally tend to be more computationally expensive. For that reason, simplest molecular structures such as: polycycles and their oxidized derivatives, are frequently employed as models of carbon based materials. ${ }^{53-56}$ Indeed, naphthalene, ${ }^{27,57,58}$ coronene, ${ }^{31-33,55,59,60}$ and their oxidized derivatives have been frequently used in theoretical studies that characterize and evaluate interactions of different molecules with these materials.

According to that, and with the aim to center the attention on the influence of AC acidic surface groups on adsorption process of CLD, the molecule of coronene, with and without a functional group attached to the edge, was used as activated carbon model. It can be seen in Figure 1, that graphene structure provides the aromatic character to the models, while the SGs at the edges of AC define the acidic or basic properties of activated carbon. As acidic surface groups, carboxylic acid $(\mathrm{COOH})$ and hydroxyl $(\mathrm{OH})$ groups, directly attached to $\mathrm{sp}^{2}$ carbons were selected, since both are the most commonly abundant oxygenated SGs found on AC surface..$^{61,62}$ To consider different $\mathrm{pH}$ conditions, deprotonated models with $\mathrm{COO}^{-}$and $\mathrm{O}^{-}$were also studied. The coronene alone was used as a reference. The water molecules were included to evaluate the explicit solvent effect in the adsorption process. This AC models were employed by Gamboa-Carballo et al., ${ }^{32}$ and Melchor-Rodríguez et al., ${ }^{33}$ when they studied the interaction of CLD and CLDh with functionalized AC at acidic, neutral and basic conditions. From their side, HernándezValdés et al., ${ }^{31}$ used it for evaluating the interactions of paracetamol and ${ }^{125}$ I-paracetamol with AC surface groups f. However, EnriquezVictorero et al. ${ }^{27}$ published a theoretical study of $\gamma$ - and $\beta-\mathrm{HCH}$ isomers interaction with $\mathrm{AC}$ surface groups, using the molecule of naphthalene as AC model.

On the other hand, two computational models of CLD have been designed, the molecule of CLD and the molecule of CLDh, considering that at $\mathrm{pH}$ value greater than 9 , chlordecone is found in its gem-diol form $\left(\mathrm{C}_{10} \mathrm{H}_{2} \mathrm{Cl}_{10} \mathrm{O}_{2}\right.$, chlordecone hydrate, Figure 2$)$, formed by substitution of carbonyl function with two hydroxyl groups. ${ }^{33}$

Following the computational procedure described here, it was stablished that the CLD-CLD intermolecular interactions are moderate, taking into consideration the values of association energy obtained by MMH methodology. Moreover, the studies concerning CLD interaction with the acidic surface groups of ACs

(c)

(d)

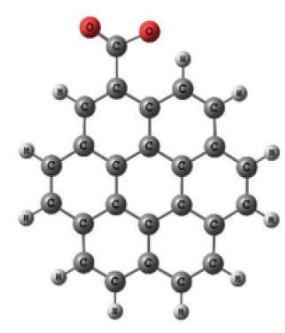

(e)

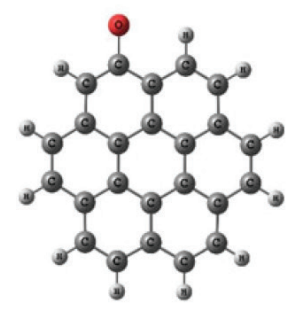

Figure 1. Activated carbon computational models: (a) coronene; the surface groups attached to the edge of AC: (b) coronene with carboxylic group (COOH) and $(c)$ coronene with hydroxyl group $(\mathrm{OH})$; and the chemical modifications of the surface groups: $(d)$ coronene with deprotonated carboxylic group (COO-) and $(e)$ coronene and deprotonated hydroxyl group $\left(\mathrm{O}^{-}\right)$ 
(a)

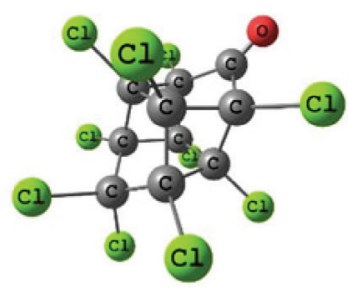

(b)

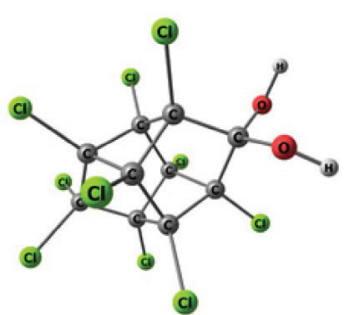

Figure 2. Chlordecone computational models: (a) chlordecone and (b) chlordecone hydrate

by Gamboa-Carballo et al., ${ }^{32}$ suggested a "little dependence of the association energy with the SG composition at low $\mathrm{pH}$ conditions $(\mathrm{pH}<5)$, where $\mathrm{COOH}$ and $\mathrm{OH}$ SGs remain mostly in neutral forms. However, at $\mathrm{pH} \approx 5-7$, which is most likely the case for drinking water, an estimation gives a deprotonation of $\mathrm{OH}$ surface groups lower than $3 \%$, while only $\mathrm{COOH}$ groups are deprotonated to a considerable extent $(\approx 90 \%) "{ }^{60}{ }^{60}$ Considering that, we can affirm that carboxylic SGs are the highest contributors to improve chlordecone adsorption onto activated carbon at slightly acidic or neutral $\mathrm{pH}$ conditions. These findings explain the experimental results obtained by Durimel et al. ${ }^{18}$ where the activated carbon with the highest amount of carboxylic surface groups resulted the best for chlordecone adsorption in water.
Nonetheless, at $\mathrm{pH}>9$ the interaction of chlordecone hydrate with $\mathrm{COO}^{-}$and $\mathrm{O}^{-} \mathrm{SG}$ is lower compare to $\mathrm{pH} \approx 5-7 .{ }^{3.3}$

Generally, comparing the $\Delta \mathrm{E}_{\mathrm{ASs} o \mathrm{C}}$ values of the systems under study in presence of CLD with the $\Delta \mathrm{E}_{\mathrm{ASSOC}}$ values of the activated carbon model with water molecules alone, the first one are considerably lower than the second one. Furthermore, the systems SG/CLD and SG/CLDh are considerably more stable than $\mathrm{SG} / \mathrm{CLD} /\left(\mathrm{H}_{2} \mathrm{O}\right)_{\mathrm{n}=1-3} \mathrm{SG} / \mathrm{CLDh} /\left(\mathrm{H}_{2} \mathrm{O}\right)_{\mathrm{n}=1-3}$ systems, although these were still energetically favored (See Table 1 ). This demeanor confirms that, if a chlordecone or CLDh molecules are associated with SGs, the water cannot compete for the adsorption sites and neither easily displace the adsorbed pesticide onto the functionalized AC. In this sense, it is important to remind that, in real systems, chlordecone is the molecule that can be found in higher concentration compare to CLDh. Also it is much diluted than CLD, for that reason, the adsorption constant of chlordecone hydrate will be displaced due to this fact.

Taking into consideration the association energies values, the affinity order of water molecules and SG was found to be $\mathrm{COO}^{-}>\mathrm{O}^{-}>\mathrm{COOH}>\mathrm{OH}>$ coronene. ${ }^{32,33}$ On the other hand, $\mathrm{COO}^{-}, \mathrm{O}^{-}$and $\mathrm{COOH}$ surface groups are been saturated when one molecule of water is added to the systems. However, to saturate $\mathrm{OH}$ surface group and coronene molecule two or three water molecules are required.

Three distinctive interaction types were obtained as result of MMH calculations (See Figure 3). The first interaction type was

Table 1. Mean association energy per water molecules $\left(\Delta \mathrm{E}_{\mathrm{ASSOC}}\right)$ for the systems $\mathrm{SG} /\left(\mathrm{H}_{2} \mathrm{O}\right)_{\mathrm{n}=1-3}, \mathrm{SG} / \mathrm{CLD} /\left(\mathrm{H}_{2} \mathrm{O}\right)_{\mathrm{n}=0-3}$ and $\mathrm{SG} / \mathrm{CLDh} /\left(\mathrm{H}_{2} \mathrm{O}\right)_{\mathrm{n}=0-3} \mathrm{values}$ are given in $\mathrm{kJ} \mathrm{mol}^{-1}$. MMH/PM7

\begin{tabular}{|c|c|c|c|c|c|c|c|c|c|c|c|}
\hline \multirow{2}{*}{ SG\n } & \multicolumn{3}{|c|}{$\mathrm{SG} /\left(\mathrm{H}_{2} \mathrm{O}\right)_{\mathrm{n}=1-3}$} & \multicolumn{4}{|c|}{$\mathrm{SG} / \mathrm{CLD} /\left(\mathrm{H}_{2} \mathrm{O}\right)_{\mathrm{n}=0-3}$} & \multicolumn{4}{|c|}{$\mathrm{SG} / \mathrm{CLDh} /\left(\mathrm{H}_{2} \mathrm{O}\right)_{\mathrm{n}=0-3}$} \\
\hline & 1 & 2 & 3 & 0 & 1 & 2 & 3 & 0 & 1 & 2 & 3 \\
\hline $\operatorname{Cor}^{\mathrm{a}}$ & -9.0 & -12.4 & -12.9 & -68.4 & -49.9 & -38.3 & -33.3 & -70.1 & -51.3 & -40.8 & -38.3 \\
\hline $\mathrm{COOH}$ & -23.8 & -16.6 & -15.7 & -74.8 & -51.0 & -38.8 & -35.2 & & & & \\
\hline $\mathrm{COO}^{-}$ & -57.2 & -45.3 & -40.5 & -123.6 & -76.2 & -64.1 & -52.9 & -144.7 & -90.2 & -69.7 & -57.8 \\
\hline $\mathrm{OH}$ & -11.9 & -14.9 & -16.0 & -69.6 & -49.0 & -36.7 & -36.2 & & & & \\
\hline $\mathrm{O}^{-}$ & -34.7 & -30.9 & -29.7 & -86.4 & -61.2 & -50.7 & -48.6 & -108.6 & -70.7 & -58.2 & -47.8 \\
\hline
\end{tabular}

a The molecule of Coronene without functional groups, used as reference.

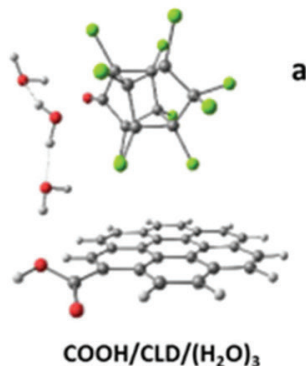

$\mathrm{COOH} / \mathrm{CLD} /\left(\mathrm{H}_{2} \mathrm{O}\right)_{3}$

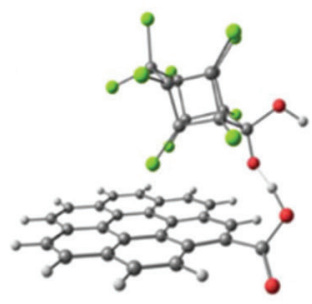

$\mathrm{COO} / \mathrm{CLDh}$ a)
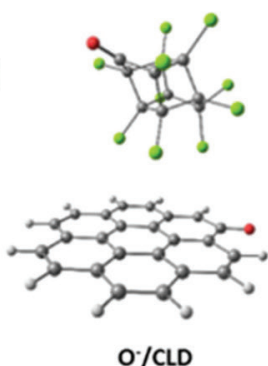

c)

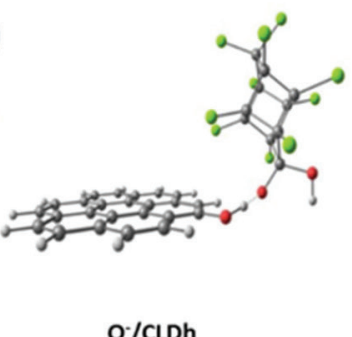

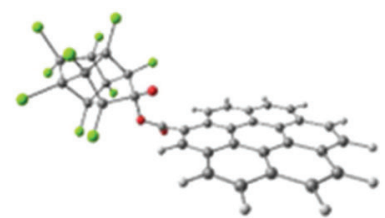

COO $/$ CLD b)

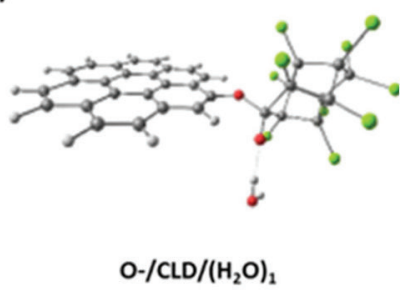

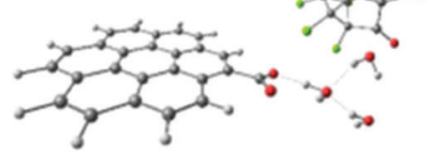

$\mathrm{COO} / \mathrm{CLD} /\left(\mathrm{H}_{2} \mathrm{O}\right)_{3}$

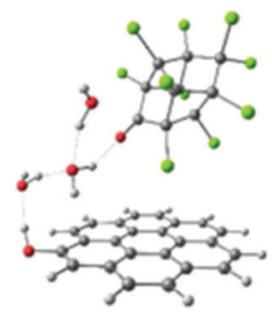

$\mathrm{OH} / \mathrm{CLO} /\left(\mathrm{H}_{2} \mathrm{O}\right)_{3}$

Figure 3. Three distinctive interaction types of CLD with protonated and deprotonated COOH and OH acidic surface groups onto AC. a) Cl $\cdots \pi$-cloud interaction; b) $\mathrm{O}^{-}$...CO interaction and c) $\mathrm{C}-\mathrm{OH} \cdots \mathrm{O}^{-}$interaction. Note in d) how water molecules network is between CLD and SGs. MMH/PM7 
predominant and it was observed between the chlorine atoms of CLD and chlordecone hydrate with the $\pi$-cloud of coronene, indicating a relatively weak interaction (Figure $3 \mathrm{a}$ ). The bonding distance was in the range of 2.3 and $3.0 \AA$, suggesting van der Waals interactions between $\mathrm{Cl}$ atoms of CLD and CLDh and the planar configuration of coronene molecule. In fact, Gamboa-Carballo et al. ${ }^{32}$ and MelchorRodríguez et al., ${ }^{33}$ reported as results of QTAIM evaluation that the dispersive interactions are mainly due van der Waals forces between chlorine atoms of pesticide and the graphitic surface in AC (see Figure $4 \mathrm{a}$ and Table 2).

As a second interaction type, a donor-acceptor interaction can be described between the negatively charged oxygen of surface groups $\left(\mathrm{COO}^{-}\right.$and $\left.\mathrm{O}^{-}\right)$and electronically deficient carbonyl carbon of chlordecone: $\mathrm{O}^{-} \ldots \mathrm{CO}$ (Figure $3 \mathrm{~b}$ ). We have underline that this interaction has not been previously described and it was observed only at slightly acidic and neutral $\mathrm{pH}$ conditions. One of the most interesting finding of Gamboa-Caraballo et al. ${ }^{32}$ is the fact that this second interaction type is only present in charged systems. In that work, "the bonding distance between the charged oxygen of the SG and the carbonylic carbon of the CLD was in the range between 1.5 and $1.6 \AA$ as results of MMH calculations. However, QTAIM calculations showed a few structures with $\mathrm{O}^{-}$...CO interactions with weak to strong covalent bonds (See Figure $4 \mathrm{~b}$ and Table 2). This result ratifies the idea of chemical sorption at slightly acidic and neutral $\mathrm{pH}$ conditions and reinforced the experimental results obtained by Durimel et al. ${ }^{18}$ through a temperature-programmed desorption studies showing that carboxylic groups at AC surface plays a major role for CLD adsorption". ${ }^{32}$

The third interaction type consists on an electrostatic interaction between the di-alcohol group of CLDh molecule and the negatively charged oxygen of SGs, represented as $\mathrm{C}-\mathrm{OH} \cdots \mathrm{O}^{-}$(Figure $3 \mathrm{c}$ ). QTAIM results confirmed this kind of interaction as seen on Figure 4c and Table 2. We have to point out that this interaction was found only

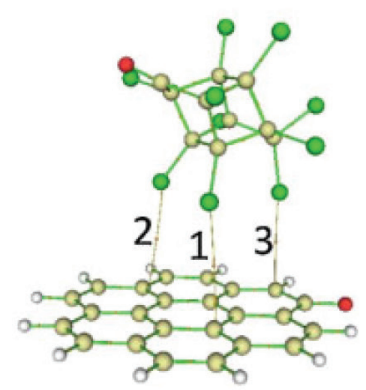

at vacuum, it means in absence of water molecules. For that reason, are will not discuss it profusely here. More information about it can be founded in the recent publication of Melchor-Rodríguez et al. ${ }^{33}$

It is important to say that the formation of $\mathrm{H}$-bonds and $\mathrm{H}$-bond clusters of water molecules, when one or two molecules of water are close to the interaction site, has be also described through $\mathrm{C}-\mathrm{OH} \cdots \mathrm{OH}_{2}$ hydrogen bonds (Figure $3 \mathrm{~d}$ ). On the other hand, concerning the aromaticity of activated carbon, two main effects have been perceived in the systems under study: 1) interactions that involve delocalized electrons of the aromatic model and, 2) the electron density stabilization was in the negatively charged SGs $\left(\mathrm{COO}^{-}\right.$and $\left.\mathrm{O}^{-}\right)$.

The DFT optimization of selected structures using CAM B3LYP/6 $31+\mathrm{G}(\mathrm{d}, \mathrm{p})^{41}$ and M06-2X functional, ${ }^{33}$ showed in most of the cases that the structures conserved their geometry and the interaction type. However, some differences for the interactions $\mathrm{Cl} \cdots \pi$-cloud were observed: while for MMH methodology with PM7 semiempirical Hamiltonian the mean interaction distances were about $2.7 \AA$, while DFT re-optimizations result in an average of 3.6 ̊. Then, it can be assumed that PM7 overestimates this kind of dispersive interactions. However, this brings an improvement in the description of other molecular properties, qualitatively describing the complexes in terms of interactions types. ${ }^{32}$

Taking into account the $\Delta \mathrm{E}_{\mathrm{ASSOC}}$ of the $\mathrm{SG} / \mathrm{CLD} /\left(\mathrm{H}_{2} \mathrm{O}\right)_{\mathrm{n}=1-3}$ and the $\mathrm{SG} / \mathrm{CLDh} /\left(\mathrm{H}_{2} \mathrm{O}\right)_{\mathrm{n}=1-3}$ systems, it was confirmed that there is no significant difference between obtained values of $\Delta \mathrm{E}_{\mathrm{ASSOC}}$ at acidic, neutral and basic $\mathrm{pH}^{32,33}$ Once again, this behavior is in agreement with practical evidences reported by Durimel et al. ${ }^{18}$ through adsorption isotherms, confirming that the best $\mathrm{pH}$ for chlordecone adsorption on activated carbons with acidic SGs ranges between 5 and 9.

Summing up, at acid $\mathrm{pH}$ where $\mathrm{COOH}$ and $\mathrm{OH}$ remain mostly in neutral forms, a very small dependence of chlordecone adsorption (a)

(b) (c)

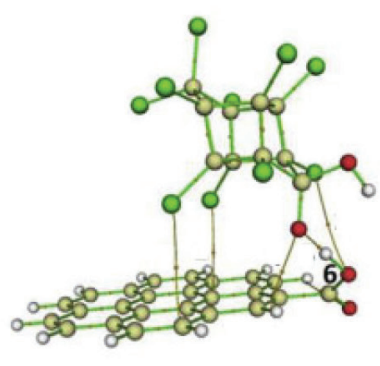

Figure 4. Interactions and bond paths obtained by QTAIM for distinctive minima structures for the systems with interactions of the type: (a) Cl $\cdots \pi$-cloud;

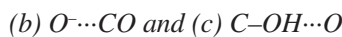

Table 2. Interatomic distances (d), electron density (BCP), Laplacian of electron density $\left(\nabla^{2} \rho_{B C P}\right)$, total energy density $\left(\mathrm{H}_{B C P}\right)$, potential-kinetic energy density ratio $\left(\mathrm{V}_{\mathrm{BCP}} / \mathrm{G}_{\mathrm{BCP}}\right)$ and ellipticity of the electron density $(\varepsilon)$ at the $\mathrm{BCPs}$ for the systems with interactions of the type: $\mathrm{Cl} \cdots \pi-\mathrm{cloud}^{-} \mathrm{O}^{-} \cdots \mathrm{CO}$ and $\mathrm{C}^{-} \mathrm{OH} \cdots \mathrm{O}^{-}$

\begin{tabular}{|c|c|c|c|c|c|c|c|c|c|}
\hline System & $\begin{array}{c}\text { Interaction } \\
\text { number }\end{array}$ & Atoms ${ }^{\mathrm{a}}$ & $\mathrm{d}(\AA)$ & $\rho_{\mathrm{BCP}}$ (a.u.) & $\nabla^{2} \rho_{\mathrm{BCP}}$ (a.u.) & $\mathrm{H}_{\mathrm{BCP}}$ (a.u.) & $\mathrm{V}_{\mathrm{BCP}} / \mathrm{G}_{\mathrm{BCP}}$ & $\varepsilon$ & Type $^{\mathrm{b}}$ \\
\hline \multirow{3}{*}{$\mathrm{O}^{-} / \mathrm{CLD}$} & 1 & $\mathrm{C} \cdots \mathrm{Cl}$ & 3.61 & 0.0042 & 0.0136 & 0.0008 & -0.7000 & 1.01 & vdW \\
\hline & 2 & $\mathrm{C} \cdots \mathrm{Cl}$ & 3.59 & 0.0045 & 0.0147 & 0.0008 & -0.7102 & 1.92 & $\mathrm{vdW}$ \\
\hline & 3 & $\mathrm{C} \cdots \mathrm{Cl}$ & 3.27 & 0.0084 & 0.0247 & 0.0012 & -0.7575 & 0.35 & $\mathrm{vdW}$ \\
\hline \multirow{2}{*}{$\mathrm{COO}^{-} / \mathrm{CLD}$} & 1 & $\mathrm{O} \cdots \mathrm{C}$ & 1.63 & 0.1599 & -0.0989 & -0.1141 & -2.2768 & 0.05 & Cov-w \\
\hline & 2 & $\mathrm{O} \cdots \mathrm{C}$ & 2.83 & 0.0134 & 0.0487 & 0.0017 & -0.8339 & 1.98 & $\mathrm{vdW}$ \\
\hline $\mathrm{COO}^{-} / \mathrm{CLDh}$ & 6 & $\mathrm{H} \cdots \mathrm{O}$ & 1.01 & 0.2328 & 1.2948 & 0.4084 & 5.8222 & 0.01 & Cov-s \\
\hline
\end{tabular}

${ }^{a}$ Atoms in the right side of the column correspond to AC model or water molecules, and atoms in the left side are of CLD. ${ }^{\mathrm{b}}$ Interaction types: vdW: van der Waals dispersive interactions; Cov-w: weak covalent interactions; and Cov-s: strong covalent interactions. 
process on surface groups was observed. However, "at $\mathrm{pH} \approx 5-7$, a rough estimation gives a deprotonation of $\mathrm{OH}$ surface groups lower than $3 \%$, while only $\mathrm{COOH}$ groups are deprotonated to a considerable extent, around $90 \% "{ }^{60}$ Then, it can be concluded that carboxylic SGs will be main contributors to improve the adsorption of chlordecone onto activated carbons at slightly acidic and neutral $\mathrm{pH}$, as demonstrated theoretical calculations, ${ }^{32}$ confirming experimental facts. ${ }^{18}$ These results suggested the possibility of chemisorption of chlordecone on charged surface groups, mainly for $\mathrm{COO}^{-}$at neutral $\mathrm{pH}$. However, at $\mathrm{pH}>9$ "both functional groups are totally deprotonated and the CLD form CLD hydrate". Therefore, from theoretical results obtained by Melchor-Rodríguez et al., ${ }^{33}$ we can summarize that "the interaction of CLDh with the acidic surface groups is favored through a dispersive and electrostatic interactions. The dispersive interactions are governed by van der Waals interactions of chlorine atoms of CLDh with the graphitic surface and electrostatic interactions by $\mathrm{H}$-bonding interactions of CLDh with SGs on AC in presence of water molecules. Finally, at $\mathrm{pH}>12$ it is suggested that the adsorption of CLD decreases again because repulsion interactions are being expected between the deprotonated CLD hydrate and the deprotonated acidic surface groups as well. Considering that, the mechanism of adsorption of CLD on acidic activated carbons at a range of $\mathrm{pH} \approx 5-7$ occurs by chemisorption and physisorption and at basic $\mathrm{pH}$ conditions by physisorption" (See Figure 5).

These results, together with the ongoing research to evaluate the role of basic groups in adsorption process, will allow deciding what are the best SGs for selecting the more adequate commercial ACs, or for an efficient synthesis of new ACs for the CLD removal from polluted waters.

\section{Trends and perspectives}

The MMH procedure has been employed for better understanding the adsorption process of chlordecone, ${ }^{32,33}$ but also of $\gamma$ and $\beta$-hexachlorocyclohexane ${ }^{19,27}$ onto functionalized activated carbon with acidic surface groups $(\mathrm{COOH}$ and $\mathrm{OH})$. For that reason, it is suggested that the proposed computational methodology might be effective to design more specific activated carbons for sorption of pesticides and others persistent organic pollutants. The use of MMH procedure allows to explore the potential interaction sites of activated carbons SGs with water molecules and the target pollutant molecule and also to calculate the thermodynamic properties of interacting system.

The use of DFT and QTAIM methods bring to us a more accurate characterization of the nature of intermolecular interactions during the adsorption process. But, the selection of calculation level, specifically the adequate selection of semiempirical Hamiltonian and of DFT functional, is always a task that demands expertise and intense search in the literature to find the procedure that furnishes the best results for each specific system. In this sense, M05, M06 and M08 Minnesota functionals, ${ }^{43}$ which have been tested lately for noncovalent interactions, appear to be promising for calculations of interactions between organochlorine compounds and functionalized activated carbon

On the other hand, inter and intra molecular interactions play an important role in determining the structure and conformation of different compounds and complexes. As shown, QTAIM has been used for characterizing the interaction types. At the same time, several theoretical approaches permit today to explain the nature of molecular interactions in adsorption processes. Among the computational methods used nowadays, NBO is one of the most popular approaches that have been extensively used.

The methodology discussed in this review will allow evaluating the influence of different surface groups on the adsorption of other organochlorine pesticides onto activated carbons, such as chlordane, dicofol, dieldrin, endosulfan, heptachlor, hexachlorobenzene, mirex and toxaphenes, that considerably affect the environmental and human health around the world. Besides, it could be extended to small organic molecules in order to design more efficient activated carbons for the removal of any particular compound, i.e drugs. In this sense, we have to focus on finding the best surface groups and operational conditions that enhance the adsorption process. It will be important

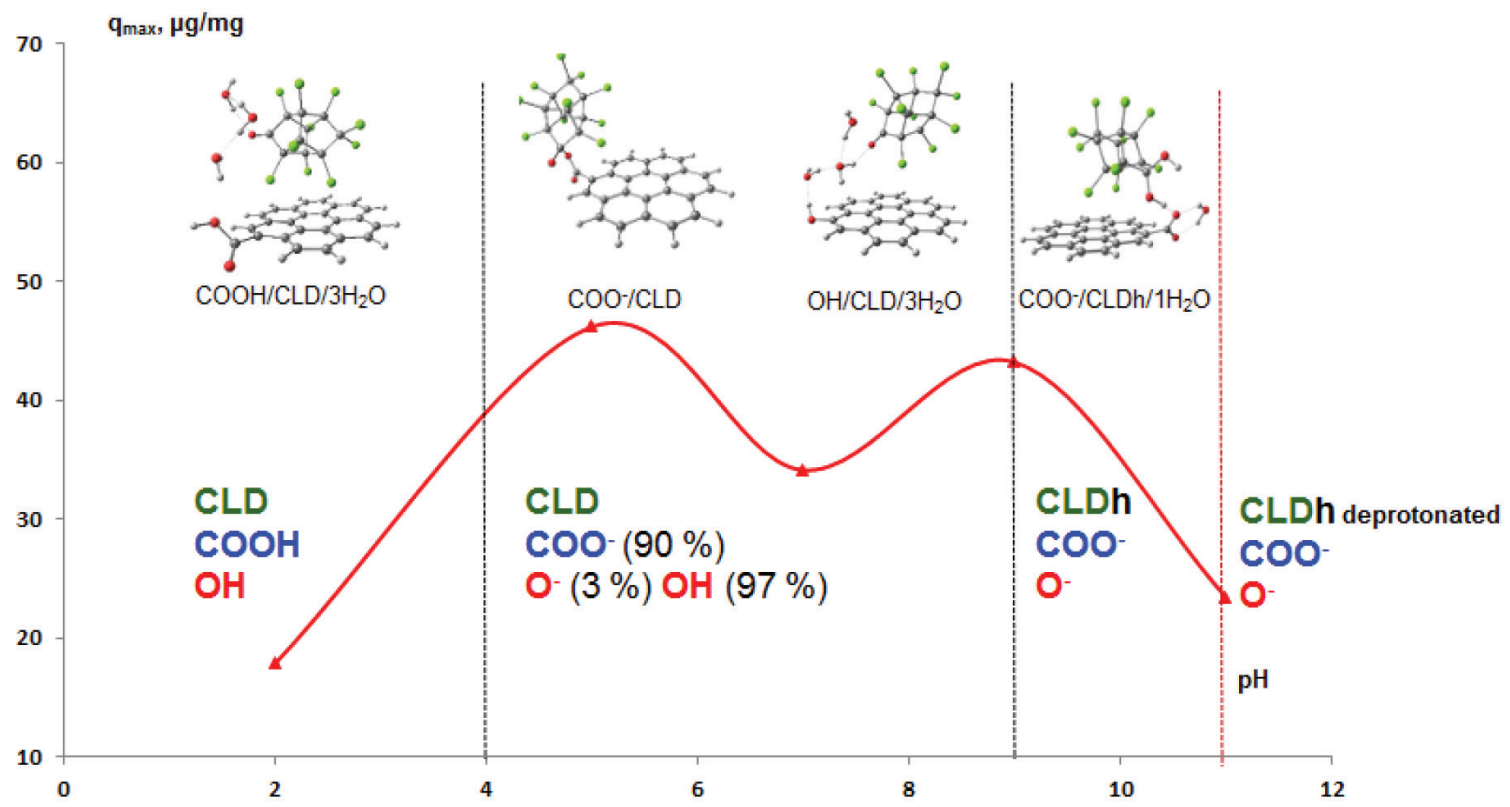

Figure 5. Relationship between experimental data by Durimel et al. ${ }^{18}$ and theoretical results by Gamboa-Carballo et al. ${ }^{32}$ and Melchor-Rodríguez et al. ${ }^{33}$ The red line represent the influence of $\mathrm{pH}$ solution on total CLD adsorption capacity (qmax) of BagP0.5 that is an AC chemically obtained from sugar cane bagasse with $\mathrm{COOH}$ as surface group. Reprinted with permission from Melchor-Rodríguez, K.; Gamboa-Carballo, J. J.; Ferino-Pérez, A.; Passe-Coutrin, N.; Gaspard, S.; Jáuregui-Haza, U. J. (2018) Theoretical study on the interactions between chlordecone hydrate and acidic surface groups of activated carbon under basic pH conditions. ${ }^{33}$ Copyright 2018 Elsevier 
to study the role of basic surfaces groups, because to date there is no any known molecular modeling study with them.

The use of other computational approaches to study molecular interactions could be important for future studies for the better understanding of adsorption process of small organic compounds onto functionalized AC or others compounds that can act as sorbents. Further computational approaches to study molecular interactions between pollutants and surface groups of activated carbons, like the electron localization function (ELF), charge decomposition analysis (CDA) and energy decomposition analysis (EDA) will be important for developing more efficient ACs. They could bring us the possibility of doing better characterization of molecular interactions and closer to quantitative elucidation of electronic structures.

Considering that chlordecone is found in the environment along with other pesticides and other inorganic or organic contaminants, the competitive adsorption between them will have to be studied. We have to underline that in real systems CLD is very diluted and, then, it has to compete also with water and several other molecules for the surface groups of activated carbon during the removal process. In this regard, neither experimental or theoretical work has been published. This requires the use of other procedures such as ab initio molecular dynamics or hybrid methods i.e. quantum mechanics/molecular mechanics (QM/MM) simulations. In fact, recent investigations applied the molecular dynamics in order to study the removal form water of pharmaceuticals, persistent organic pollutants or simply organic compounds by adsorption onto AC. . $^{63,64}$

Finally, another challenge will be to carry out more complex modeling studies, where in addition to the chemical nature of the SGs, the morphology and topology of the activated carbons are taken into account. Indeed, Huang et al.,${ }^{65}$ showed that "the construction of large-scale atomistic representations of activated carbon aids the exploration of structure-property relationships. Fringe3D and Vol3D perl script in conjunction with Materials Studio were used to facilitate the construction process. The proposed computational protocol offered a highly efficient approach for constructing largescale atomic representations without high computational cost. This modeling protocol resulted in greater experimental conformity, improved accuracy, and structural diversity. Evaluation of the physical parameter showed good agreement with experimental characterizations such as porosity, elemental composition, oxygen functionality, and pore size distribution".

\section{CONCLUSIONS}

Computational chemistry is as powerful tool to complement experimental research in the field of pollutants adsorption. The versatility and accuracy of computational chemistry to explain and predict intermolecular interactions and molecular properties between adsorbants and adsorbents is a valuable, economic and fast enough approach to study complex molecular systems. The developed procedure that combines the semiempirical Multiple Minima Hypersurface methodology with Density Functional Theory allowed a better understanding the interaction of chlordecone with acid surface groups of activated carbons. As next step, a clear focus has to be set on investigating the influence of different surface groups (like basic ones); other more complex models of activated carbons that take into account not only surface chemistry but also pore morphology and topology; and the competitive adsorption of other pollutants on chlordecone adsorption onto activated carbons. The synergy between experiment and theory is essential to aid in the development process of new and more efficient activated carbons for the purification of waters contaminated with chlordecone and other persistent organic compounds. The characterization of molecular interactions and the operational conditions ( $\mathrm{pH}$ and solvation) in the context of competitive adsorption using computational chemistry will be of high importance in the near future. Despite the fact that most of this is nowadays possible, the development of new or improved methods, together with the increasing of computational power will make the use of computational chemistry more valuable to understand the chlordecone and other pesticides adsorption processes and also assist in the optimization and development of new activated carbons that can be more effective to water decontamination.

\section{ACKNOWLEDGEMENTS}

The authors thanks to Yesapín García for her valuable comments.

\section{REFERENCES}

1. Padmanabhan, J.; Parthasarathi, R.: Subramanian, V.; Chattaraj P. K.; J. Phys. Chem. A 2006, 110, 2739.

2. Almeida, F. V.; Centeno, A. J.; Bisinoti, M. C.; Jardim, W. F.; Quim. Nova 2007, 30, 1976.

3. Rebelo, R. M.; Caldas, E. D; Quim. Nova 2014, 37, 1199.

4. Montagner, C. C.; Vidal, C.; Acayaba, R. D.; Quim. Nova 2017, 40, 1094.

5. Epstein, S.; Sci. Total Environ. 1978, 9, 1.

6. Multigner, L.; Kadhel, P.; Rouget, F.; Blanchet, P.; Cordier, S.; Environ. Sci. Pollut. Res. 2016, 23, 3.

7. Bro-Rasmussen, F.; Sci. Total Environ. 1996, 188, 45.

8. Clostre, F.; Letourmy, P.; Lesueur-Jannoyer, M.; Chemosphere 2015 , $118,96$.

9. Cabidoche, Y. M.; Achard, R.; Cattan, P.; Clermont-Dauphin, C.; Massat, F.; Sansoulet, J.; Environ. Pollut. 2009, 157, 1697.

10. Cabidoche, Y. M.; Lesueur-Jannoyer, M.; Pedosphere 2012, 22, 562.

11. Coat, S.; Bocquené, G.; Godard, E.; Aquat. Living Resour. 2006, 19, 181.

12. Jondreville, C. ; Lavigne, A.; Jurjanz, S.; Dalibard, C.; Liabeuf, J.M.; Clostre, F.; Lesueur-Jannoyer, M.; Sci. Total Environ. 2014, 493, 336.

13. Cordier, S.; Bouquet, E.; Warembourg, C.; Massart, C.; Rouget, F.; Kadhel, P.; Environ. Res. 2015, 138, 271.

14. Lagarrigue, M.; Lavigne, R.; Tabet, E.; Genet, V.; Thomé, J.P.; Rondel, K.; Anal. Chem. 2014, 86, 5775.

15. Merlin, C.; Devers, M.; Béguet, J.; Boggio, B.; Rouard, N.; MartinLaurent, F.; Env. Sci. Pollut. Res. 2016, 23, 4185.

16. Cornish, A. S.; Ng, W. C.; Ho, V. C. M.; Wong, H. L.; Lam, J. C. W.; Lam, P. K. S.; Leung, K. M. Y.; Sci. Total Environ. 2007, 376, 335.

17. Roche, H.; Salvat, B.; Ramade, F.; Rev. Ecol. 2011, 66, 3.

18. Durimel, A.; Altenor, S.; Miranda-Quintana, R.A.; Couespel Du Mesnil, P.; Jáuregui-Haza, U.; Gadiou, R.; Gaspard, S.; Chem. Eng. J. 2013, 229, 239.

19. Durimel, A.; Passé-Coutrin, N.; Jean-Marius, C.; Gadiou, R.; EnriquezVictorero, C.; Hernández-Valdés, D.; Jáuregui-Haza, U.; Gaspard, S.; RSC Adv. 2015, 5, 85153.

20. Rana, V. K.; Kissner, R.; Gaspard, S.; Levalois-Grützmacher, J.; Chem. Eng. J 2016, 293, 82.

21. Dromard, C. R.; Bodiguel, X.; Lemoine, S.; Bouchon-Navaro, Y.; Reynal, L.; Thouard, E.; Bouchon, C.; Env. Sci. Pollut. Res. 2016, 23, 73.

22. Crabit, A.; Cattan, P.; Colin, F.; Voltz, M.; Environ. Pollut. 2016, 212, 615.

23. Fournier, A. ; Feidt, C.; Lastel, M.L.; Archimede, H.; Thome, J.P.; Mahieu, M.; Rychen, G.; Chemosphere 2017, 171, 564.

24. Hervé, D.; Costet, N.; Kadhel, P.; Rouget, F.; Monfort, C.; Thomé, J. P.; Cordier, S.; Environ. Resour. 2016, 151, 436

25. Nedellec, V.; Rabl, A., Dab, W.; Environ. Health 2016, 15, 78. 
26. Devault, D. A.; Karolak S.; Lévi, Y.; Rousis, N.I.; Zuccato, E.; Castiglioni, S.; Sci. Total Environ. 2018, 644, 129.

27. Enriquez-Victorero, C.; Hernández-Valdés, D.; Montero-Alejo, A.L.; Durimel, A.; Gaspard, S.; Jáuregui-Haza, U.; J. Mol. Graphics Modell. 2014, 51, 37

28. Rana, V. K.; Kissner, R.; Jauregui-Haza, U.; Gaspard S, LevaloisGrützmacher, J.; J. Environ. Chem. Eng. 2017, 5, 1608.

29. Kalderis, D.; Koutoulakis, D.; Paraskeva, P.; Diamadopoulos, E.; Otal, E.; Valle, J.O.; Fernandez-Pereira, C.; Chem. Eng. J. 2008, 144, 42.

30. Valix, M.; Cheung, W.H.; Zhang, K.; J. Hazard. Mater. 2006, 135, 395.

31. Hernández-Valdés, D. ; Enriquez-Victorero, C.: Pizarro-Lou, L.; TuriñoPérez, D.; Ducat-Pagés, L.; Arias, M.; Jáuregui-Haza, U.; J. Radioanal. Nucl. Chem. 2015, 305, 609.

32. Gamboa-Carballo, J. J.; Melchor-Rodríguez, K., Hernández-Valdés, D., Enriquez-Victorero, C., Montero-Alejo, A.L.; Gaspard, S.; JaureguiHaza, U.; J. Mol. Graphics Modell. 2016, 65, 83.

33. Melchor-Rodríguez, K.; Gamboa-Carballo, J. J.; Ferino-Pérez, A.; PasseCoutrin, N.; Gaspard, S.; Jáuregui-Haza, U. J.; J. Mol. Graphics Modell. 2018, 81, 146.

34. Montero, L. A.; Esteva, A.M.; Molina, J.; Zapardiel, A.; Hernández, L.; Márquez, H.; Acosta, A.; J. Am. Chem. Soc. 1998, 120, 2023.

35. Hernández-Valdés, D.; Enríquez-Victorero, C.; Jáuregui-Haza, U.; Hernández, P.; González-Santana, S.; Revista Cubana de Ciencias Informáticas 2013, 7, 9.

36. Stewart, J. J. P.; J. Mol. Model. 2013, 19, 32.

37. Hostaš, J.; Řezáč, J.; Hobza, P.; Chem. Phys. Lett. 2013, 568, 161.

38. Stewart, J. J. P.; MOPAC2012, Stewart Computational Chemistry, Colorado Springs, CO, USA, 2012.

39. Stewart, J. J. P.; MOPAC2016, Stewart Computational Chemistry, Colorado Springs, CO, USA, 2016.

40. Jensen, B.; Kuznetsova, T.; Kvamme, B.; Oterhals, A.; Fluid Phase Equilib. 2011, 307, 58.

41. Yanai, T.; Tew, D. P.; Handy, N. C.; Chem. Phys. Lett. 2004, 393, 51.

42. Limacher, A. P.; Mikkelsen, K. V.; Lüthi, H. P.; J. Chem. Phys. 2009, 130.

43. Zhao, Y.; Truhlar, D. G.; Theor. Chem. Account 2008, 120, 215.

44. Walker, M.; Harvey, A. J. A.; Sen, A.; Dessent, C. E. H.; J. Phys. Chem. A 2013, 117, 12590 .

45. Goerigkab, L.; Grimme, S.; Phys. Chem. Chem. Phys. 2011, 13, 6670.

46. Peverati, R.; Truhlar, D. G.; Rev. Trans. R. Soc. A 2013.

47. Kobayashi, R.; Amos, R. D.; Chem. Phys. Lett. 2006, 420, 106.

48. Okuno, K.; Shigeta, Y.; Kishi, R.; Miyasaka, H.; Nakano, M.; J. Photochem. Photobiol. A. 2012, 235, 29.

49. Frisch, M. J.; Trucks, G. W.; Schlegel, H. B.; Scuseria, G. E.; Robb, M. A.; Cheeseman, J. R.; Scalmani, G.; Barone, V.; Petersson, G.
A.; Nakatsuji, H.; Li, X.; Caricato, M.; Marenich, A. V.; Bloino, J.; Janesko, B. G.; Gomperts, R.; Mennucci, B.; Hratchian, H. P.; Ortiz, J. V.; Izmaylov, A. F.; Sonnenberg, J. L.; Williams-Young, D.; Ding, F.; Lipparini, F.; Egidi, F.; Goings, J.; Peng, B.; Petrone, A.; Henderson, T.; Ranasinghe, D.; Zakrzewski, V. G.; Gao, J.; Rega, N.; Zheng, G.; Liang, W.; Hada, M.; Ehara, M.; Toyota, K.; Fukuda, R.; Hasegawa, J.; Ishida, M.; Nakajima, T.; Honda, Y.; Kitao, O.; Nakai, H.; Vreven, T.; Throssell, K.; Montgomery, J. A., Jr.; Peralta, J. E.; Ogliaro, F.; Bearpark, M. J.; Heyd, J. J.; Brothers, E. N.; Kudin, K. N.; Staroverov, V. N.; Keith, T. A.; Kobayashi, R.; Normand, J.; Raghavachari, K.; Rendell, A. P.; Burant, J. C.; Iyengar, S. S.; Tomasi, J.; Cossi, M.; Millam, J. M.; Klene, M.; Adamo, C.; Cammi, R.; Ochterski, J. W.; Martin, R. L.; Morokuma, K.; Farkas, O.; Foresman, J. B.; Fox, D. J.; Gaussian 09, Revision A. 01, Gaussian, Inc.: Wallingford CT, 2009.

50. Bader, R. F. W.; Chem. Rev 1991, 91, 893.

51. Nakanishi, W., Hayashi, S.; Narahara, K.; J. Phys. Chem. A 2008, 112, 13593.

52. Nakanishi, W.; Hayashi, S.; Narahara, K.; J. Phys. Chem. A 2009, 113, 10050.

53. Lazar, P.; Zhang, S.; Šafářová, K.; Li, Q.; Froning, J. P.; Granatier, J.; ACS Nano 2013, 7, 1646.

54. Lazar, P.; Karlicky, F.; Jurečka, P.; Kocman, M.; Otyepková, E.; Šafářová, K.; J. Am. Chem. Soc. 2013, 135, 6372.

55. Granatier, J.; Lazar, P.; Otyepka, M.; Hobza, P.; J. Chem. Theor. Comput. 2011, 7, 3743.

56. Granatier, J.; Lazar, P.; Prucek, R.; Šafářová, K.; Zbořil, R.; Otyepka, M.; J. Phys. Chem. C 2012, 116, 14151.

57. Cabaleiro-Lago, E. M.; Rodríguez-Otero, J.; Peña-Gallego, A.; J. Phys. Chem. A 2008, 112, 6344 .

58. Cho, Y.; Min, S. K.; Yun, J.; Kim, W. Y.; Tkatchenko, A.; Kim, K. S.; J. Chem. Theor. Comput. 2013, 9, 2090.

59. Oubal, M.; Picaud, S.; Rayez, M. T.; Rayez, J. C.; Surf. Sci. 2010, 604, 1666.

60. Picaud, S.; Collignon, B.; Hoang, N. M.; Rayez, J. C.; Phys. Chem. Chem. Phys. 2008, 10, 6998.

61. De la Puente, G.; Pis, J. J.; Menéndez, J. A.; Grange, P.; J. Anal. Appl. Pyrolysis 1997, 43, 125.

62. Figueiredo, J. L.; Pereira, M. F. R.; Freitas, M. M. A.; Órfao, J. J. M.; Carbon 1999, 37, 1379.

63. Bahamon, D.; Carro, L.; Guri, S.; Vega, L. F.; J. Colloid Interface. Sci. 2017, 498, 323.

64. Terzyk, A. P.; Gauden, P. A.; Zielinski, W.; Furmaniak, S.; Wesołowski, R. P.; Klimek, K. K.; Chem. Phys. Lett. 2011, 515, 102.

65. Huang, Y.; Cannon, F. S.; Watson, J. K.; Reznik, B.; Mathews, J. P.; Carbon 2015, 83, 1. 